\title{
Accounting for preference dependency in target costing - a note
}

\author{
Carsten Homburg $^{1} \cdot$ André Hoppe $^{1} \cdot$ Roman Schick $^{1}$ (D) $\cdot$ Amelie Braul $^{1}$
}

Accepted: 13 February 2021 / Published online: 8 March 2021

(c) The Author(s) 2021

\begin{abstract}
Target costing is a well-established strategic cost management tool in theory and practice. The original target costing model implies independence of customer preferences resulting in additive utility functions for the customer-oriented optimization of cost structures. We argue that this independence of preferences is not given until a minimum variant of a product is reached that provides its inherent functionality. This is reasonable since one cannot assign customer utility to a product that does not function in its most basic way. Our modified model accounts for the dependency of customer preferences and differentiates between the costs necessary to produce a minimum variant and those related to product features beyond this minimum variant. The customer-oriented optimization of the cost structure is then conducted only for those costs that exceed the costs of the minimum variant. This modification justifies the preference independence assumption in target costing and allows for a more reasonable assignment of required adjustments in costs per product component.
\end{abstract}

Keywords Target costing $\cdot$ Customer preference independence $\cdot$ Minimum variant $\cdot$ Cost allocation

JEL C02 $\cdot$ M10 $\cdot$ M41

\section{Introduction}

Traditional pricing models primarily take a firm-oriented view in that the price is calculated by adding a profit margin on top of the incurred costs (e.g., Ewert and Ernst 1999). However, research highlights the importance of customer satisfaction in setting the price of a product (e.g., Woratschek 1995). The strategic cost management tool "target costing" implements the concept of customer-orientation into pricing (Hiromoto 1988). In both literature and practice target costing is highly relevant. Yazdifar and Askarany (2012) analyze the use of target costing amongst manufacturers and service firms. They stress the

Roman Schick

schick@wiso.uni-koeln.de

1 Department of Business Administration and Management Accounting, University of Cologne, Cologne, Germany 
importance of cost control techniques such as target costing in the steadily increasing competitive environment.

According to Kato (1993), the target costs and, therefore, the allowable costs (AC) are calculated as the expected sales price less the targeted profit. ${ }^{1}$ Target costing uses customer preference analysis to identify the implementable price and future sales volume (Kato 1993). The product's cost structure is then optimized by matching drifting costs (DC), i.e., the actual current production costs for a given production technology, with the required level of AC (Sakurai 1989; Ewert and Ernst 1999). The costing mechanism helps assign reasonable costs to products, matching customers' respective utility. This optimization assumes the independence of customer preferences resulting in an additive utility function (see Woratschek 1995 and Keeney 1970). We posit that this assumption does not hold generally, since additive utility functions are reasonable only for product features beyond a minimum variant of the product that fulfills its most basic functions. Coenenberg et al. (2003) illustrate an example for target costing which identifies the existence of a minimum variant of a product. However, they do not account for this minimum variant in their actual calculations. Götze and Linke (2008) recognize the limitation of the assumption of preference independencies. Yet, they do not provide a solution for the application of target costing regarding preference dependencies. In this note, we propose a modification of target costing that accounts for the minimum variant of a product. Our model differentiates between costs necessary to produce the minimum variant and costs for product features beyond that. Only the latter costs in excess of the minimum variant's costs are then subject to customer-oriented cost structure optimization. This leads to a more realistic match of the product components' cost allocation and the utility they provide. With our modified model, the assumption of an additive utility function for the minimum variant becomes obsolete.

While target costing is widely used in Japanese companies (Yoshikawa et al. 1995), target costing also gained widespread recognition beyond the borders of Japan. E.g., Dekker and Smidt (2003) analyze the practice of Dutch firms engaging in costing systems, which are much like the Japanese target costing model. They conclude that practices very similar to target costing have been implemented across industries, in particular in manufacturing firms. Moreover, Ellram (2006) and Everaert et al. (2006) investigate the implementation and practice of target costing within companies in the US and Europe. They find that the practical adoption of target costing in companies is generally in line with the theoretical model of target costing. ${ }^{2}$ Mouritsen et al. (2001) use a case study to analyze the extent to which target costing can be used as a management control mechanism within the company and across companies in the case of outsourcing (e.g., the product development department). They find that management control is supported by the analysis of costs and customer value of different functions in a product. In contrast to the above-mentioned studies, Navissi and Sridharan (2017) focus on the internal factors influencing the use of target costing. They show that target costing offers quite accurate assessments of product profitability and that senior management that is compensated based on its projects' profitability

\footnotetext{
1 According to Coenenberg et al. (2003), a "narrower" calculation of AC can also be defined as sales forecasts less the aimed profit margin less the budget for selling, general, and administrative expenses. We use this calculation method for the remainder of this paper, which additionally accounts for overhead costs. However, our assertions remain the same when using the other definition.

${ }^{2}$ Everaert et al. (2006) find that in one case target costing was not well established because of the company culture. They argue that in this specific case the company struggled with implementing a cost-reduction philosophy. Before the introduction of target costing, the company was engineering driven. Further, cost reduction options in the problematic company were more limited than in other cases.
} 
favors the use of target costing. Tani et al. (1994) explore the extent to which target costing is used in different industries. They find that in industries with low product diversity, target costing practices are mostly adopted for all models. Conversely, in the automobile industry, due to a wide variety of automobile models in each category, target costing is only applied to a so-called pre-determined base model. This pre-determined base model should not be confused with our minimum variant. The minimum variant is met as soon as the product is functional, while their proposed base model includes features beyond that.

The need for a better understanding of target costing, its basic assumptions and its relevance becomes evident when considering firm goals. Low cost and high product quality leading to customer satisfaction are often competing goals. For many companies, cost reduction is the main objective when engaging in target costing practices (Tani et al. 1994). However, the target costing approach can support companies in maximizing both goals_-low cost and high product quality—simultaneously. Making tradeoff decisions at the product development stage leads to optimized cost and quality at the very beginning of the product's life cycle (Dekker and Smidt 2003; Tani 1995). ${ }^{3}$ Ibusuki and Kaminski (2007) study target costing in conjunction with value engineering in the automobile industry. Their results show that the use of value engineering is complementary to target costing. While target costing enables a strong performance of cost planning, value engineering increases the chance of reaching the cost targets and guaranteeing quality at the same time. With our modified model, which accounts for preference dependencies, the assignment of $\mathrm{AC}$ to the different product components is more reasonable. This further improves the optimization of cost and quality in the product development stage.

\section{Theoretical framework}

\subsection{Target costing}

After preliminary market research and future sales volume planning, the target costing model starts by calculating the AC:

$$
A C=\text { Price } \cdot(1-\text { Profit Margin }) \cdot \text { Volume }-S G \& A \text { Expense } .
$$

The AC are then compared to the product's DC to determine the cost gap. If the DC are higher than the $\mathrm{AC}$, the implication is to perform cost splitting and to optimize the cost structure in a customer-oriented way to approximate the DC to the AC (e.g., Kato 1993). For the customer-oriented optimization of cost structure, the block of target costs is split with respect to customer utilities instead of using total AC. Within the customer preference analysis, utility values are assigned to each feature of the product (Woods et al. 2012). The product's features result from the product's components used and the assigned feature utilities are proportionally matched with their components. To derive the allowable costs $\left(A C_{i}\right)$ per component $i$, total AC are split upon the product's components based on the utility proportion each component provides (Woods et al. 2012). Conversely, if DC are smaller than or equal to the $\mathrm{AC}$, then the product's cost structure is optimal if the proportion of

\footnotetext{
3 Tani (1995) provides insight into how simultaneous engineering is used in target costing to achieve the early planned cost reductions in the production stage later in the product's life cycle.
} 
component $i$ 's utility value is equal to the proportion of component $i$ 's drifting costs $\left(D C_{i}\right)$. The ratio of both is then defined as the Target Cost Index $\left(T C I_{i}\right)$ of component $i$ :

$$
T C I_{i}=\frac{\sum_{j=1}^{J}\left(u_{j} \cdot v_{i j}\right)}{\frac{D C_{i}}{D C}},
$$

where $\mathbf{J}$ denotes the total number of features, $u_{j}$ denotes the utility of feature $j$, and $v_{i j}$ the share of component $i$ in contributing to feature $j$ with $\sum_{i=1}^{I} v_{i j}=1$. This index contains information about the relative cost-(in) efficiency of each component $i$. If the $T C I_{i}$ is not equal to one for all components of a product, costs should also be optimized through customer-oriented optimization of the cost structure, irrespective of DC being smaller than or equal to AC. This step is economically intuitive because even though the DC might be smaller than or equal to the $\mathrm{AC}$, the costs for some components are too high or too low relative to their contribution to the product's total utility. Through a cost-value analysis by using the $T C I_{i}$, management can analyze into which component $i$ it should invest (divest) in accordance with a high (low) customer utility of the component. Therefore, the customer's willingness to pay increases for features with high utility and cost decreases for features with low utility. In case the component is too costly relative to the attributed customer utility, $D C_{i}$ have to be reduced to reach $A C_{i}$. Cost optimization is completed when it applies that $D C_{i}$ are equal to $A C_{i}$ for each component $i$ (Sakurai 1989; Woods et al. 2012).

\subsection{Target costing including a minimum variant}

The theoretical framework above hinges on the assumption that customer preferences are independent and, thus, on the additivity of their utility functions (Woratschek 1995). In accordance with Götze and Linke (2008), we argue that this assumption is economically plausible only if specific minimum requirements are met. ${ }^{4}$ As an example, consider a car without wheels but an engine that leads to high customer utility. Such a car should still have a total utility of zero since it cannot function without wheels. Accordingly, we cannot add up utility values of a product's components until the product's intended minimum functions are provided. Coenenberg et al. (2003) introduce a minimum variant of a product that has features with a customer value of zero. Their example implies that these features are not leading to an increase in costs compared to the costs for the minimum variant. Nevertheless, features with zero utility for the customer, still face costs in production. The implication of a strict interpretation of target costing would be to reduce costs to zero for all features that have a customer utility of zero. However, for a minimum variant of a product, it is reasonable to implement the features while having costs greater than zero. To support this thought, we revisit the car example and consider a functioning car without any special features as our minimum variant. According to the framework, this car has zero customer utility. Yet, the production of this car still leads to costs for the company. Only after reaching the minimum requirements of the car, we can go further and add features that lead to customer utility. Coenenberg et al. (2003) acknowledge the existence of a minimum variant, but do not account for a solution for the model's violation to have costs for features with zero utility. Furthermore, an additive utility function is still used for the total

\footnotetext{
${ }^{4}$ Keeney (1970) generally addresses the restrictive assumptions that are required in order to use the additive utility function.
} 
amount of costs including the cost for the minimum variant. Therefore, the aforementioned limitation of target costing is not solved. Götze and Linke (2008) start to address this limitation. They assume that specific basic requirements of a product must be attained before an additive utility function can be used. More precisely, they do not include the costs for the basic requirements in the calculations for cost-optimization, which is in line with our framework. Yet, they do not specify how to treat costs for the basic requirements considering that they have zero utility for the customer but lead to costs for the company.

Based on the limitation of target costing not accounting for the dependence of features and preferences until the minimum requirements of a product are reached, we integrate a minimum variant in the modified target costing approach. To facilitate comprehension of our following theoretical model framework, we provide a numerical example in the appendix. We argue that a customer-oriented optimization for product components is economically unreasonable until the production of a minimum variant is achieved. Our basic idea, which distinguishes our note from previous work, is to disaggregate $\mathrm{AC}$ into allowable costs to achieve the minimum variant $(\underline{A C})$ and allowable costs to achieve the presently favored variant $(\overline{A C})$. The favored variant of a product is characterized by offering features that go beyond the minimum requirements and are demanded by customers in the market. For the process of customer-oriented splitting of target costs we only take into account the block of costs that does not include $\underline{A C}$ :

$$
A C^{\text {mod }}=\overline{A C}-\underline{A C},
$$

where $A C^{\text {mod }}$ denotes the modified allowable costs. Along with the definition above, the customer-oriented optimization of costs of product components is conducted for the DC that do not include $\underline{A C}$. With $\overline{D C}$ denoting the drifting costs of our favored variant, we define our modified drifting costs $\left(D C^{\text {mod }}\right)$ as follows:

$$
D C^{\text {mod }}=\overline{D C}-\underline{A C} .
$$

It is crucial that we do not subtract the drifting costs $(D C)$ of our minimum variant to receive $D C^{\text {mod }}$. In general, $\underline{D C}$ are higher than $\underline{A C}$. Using $\underline{D C}$ to calculate $D C^{\text {mod }}$ would lead to biased modified drifting costs. Therefore, the cost would not be completely optimized since the gap between $D C^{\text {mod }}$ and $A C^{\text {mod }}$ would be smaller. At this point, it is important to underline that the modified target costing leads to the same amount of required adjustment in cost as the original target costing model. The difference lies in the allocation of required adjustments on the component level. With the modified target costing approach, allowable costs are assigned more reasonably to the product's components.

As for original target costing, the implication for the customer-oriented optimization is to stop the optimization process when $D C^{\text {mod }}$ are smaller than or equal to $A C^{\text {mod }}$. Hence, $\overline{D C}$ are smaller than or equal to $\overline{A C}^{5}$ :

$$
\overline{D C}-\underline{A C} \leq \overline{A C}-\underline{A C} \Leftrightarrow \overline{D C} \leq \overline{A C} .
$$

For the minimum variant, we define a customer value equal to zero. If the customer value of a product is zero, it means that the minimum variant is produced and that the

\footnotetext{
5 As specified above for target costing, the fact that $D C^{\text {mod }}$ are smaller than or equal to $A C^{\text {mod }}$ does not automatically imply that costs are optimal on the component level as well. Therefore, the implication only holds in general. However, to be exact one would have to check the component level as well.
} 
favored variant of the product matches the minimum variant. According to this assumption, $\underline{A C}$ are equal to $\overline{A C}$, leading to $A C^{\text {mod }}$ of zero in Eq. (3). Therefore, customeroriented splitting of target costs is not conducted since $A C^{\text {mod }}$ are the only block of costs for which one would conduct customer-oriented splitting of target costs. In case a company only produces the minimum variant, it is required that the product is produced with the respective $A C$. For a company to be able to produce a product with the respective $\underline{A C}, \underline{A C}_{i}$ need to be computed. The calculation of $\underline{A C}$ differs from the determination of $A C_{i}$, since we do not use customer-oriented splitting of target costs. To define $A C_{i}$, drifting costs for the minimum variant per component $\underline{D C}_{i}$ are reduced by an identical factor $A C / \underline{D C}$. This factor can be considered as a measure for the gap to a hypothetical ideal company in the "low-cost segment":

$$
\underline{A C}_{i}:=\frac{\underline{\overline{D C}}}{\underline{D C}} \cdot \underline{D C}_{i} .
$$

For this calculation we only need to determine $\underline{A C}$, assuming information about $\underline{D C}$ and $\underline{D C}$ are given. Even though we do not conduct customer-oriented splitting of target costs for the minimum variant, the framework still determines the total $\underline{A C}$ with respect to market-orientation. We use $A C$ from Eq. (1) with the implementable price and sales volume for a minimum product. Here, the implication is to stop the adjustment of costs when $\underline{D C}$ equaling $\overline{D C}$ are smaller than or equal to $\underline{A C}$ equaling $\overline{A C}$ :

$$
\underline{D C}=\overline{D C} \leq \overline{A C}=\underline{A C} .
$$

We further highlight that, by introducing $\mathrm{AC}$ in our model for modified target cost-

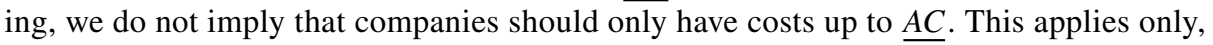
if companies are actually producing the minimum variant as discussed above. In the case of a company, which operates in a differentiated high-quality segment instead of a low-price segment, it could be reasonable to produce a favored variant of the product for which actual costs exceed the costs of a minimum variant. E.g., most car manufacturers do not produce cars which are only supposed to fulfill the minimum requirements of a car. Consequently, their production costs for the favored variant are not restricted to $A C$.

If a company produces a favored variant of a product that adds features to the minimum variant, these costs in excess of $\underline{A C}$ can be optimized on the basis of customeroriented target cost splitting. As argued above, the independence of preferences and therefore, an additive utility function can be implied after reaching the minimum variant of a product and does not cause any distortions in our model. Consequently, utilities can be added or subtracted based on customer preferences. $A C^{\text {mod }}$ can be seen as the respective costs for these added features that lead to higher customer utility. Consequently, it is reasonable to use $A C^{\text {mod }}$ from Eq. (3) for the customer-oriented splitting of target costs. Since production goes beyond the minimum variant, the company is not required to reach $\underline{A C}$. However, to calculate $A C^{\text {mod }}, \overline{A C}$ have to be determined. We use $A C$ from Eq. (1) with the implementable price and sales volume for the favored product to determine $\overline{A C}$. With available information on $\overline{D C}, D C^{\text {mod }}$ can be calculated according to Eq. (4). To conduct the customer-oriented optimization of the cost structure of a product, total $A C^{\text {mod }}$ have to be split based on the customer utilities to receive the modified allowable costs $\left(A C_{i}^{\text {mod }}\right)$ per component $i$. Further, the modified drifting costs per component $D C_{i}^{\text {mod }}$ have to be calculated. To receive $A C_{i}^{\text {mod }}$, we use the known 
customer-oriented splitting of target costs for the residuum of costs after deducting $\underline{A C}_{i}$. The total $A C^{\text {mod }}$ are weighted by the utility proportion of the $i^{\text {th }}$ component.

$$
A C_{i}^{\text {mod }}=\sum_{j=1}^{J}\left(u_{j} \cdot v_{i j}\right) \cdot A C^{\text {mod }},
$$

where $u_{j}$ denotes the utility of feature $j$, and $v_{i j}$ the share of component $i$ in contributing to feature $j$ with $\sum_{i=1}^{I} v_{i j}=1$. The total allowable costs $\left(\overline{A C}_{i}\right)$ for the favorable variant of component $i$ are the sum of $A C_{i}^{\text {mod }}$ and $\underline{A C}$.

$$
\overline{A C}_{i}:=\frac{\underline{A C}}{\underline{D C}} \cdot \underline{D C}+\sum_{j=1}^{J}\left(u_{j} \cdot v_{i j}\right) \cdot A C^{\bmod } .
$$

For given $\overline{D C}$ and drifting costs $\left(\overline{D C}_{i}\right)$ of the favored variant per component $i, D C^{\text {mod }}$ and modified drifting costs $\left(D C_{i}^{\text {mod }}\right)$ per component $i$ can be calculated by subtracting $\underline{A C}$ and $\underline{A C}_{i}$ from $\overline{D C}$ and $\overline{D C}_{i}$, respectively.

$$
\begin{aligned}
D C^{\text {mod }} & :=\overline{D C}-\underline{A C} \\
D C_{i}^{\text {mod }} & :=\overline{D C}_{i}-\underline{A C_{i}} .
\end{aligned}
$$

To perform a cost-value analysis for the product components, the proportion of $D C_{i}^{\text {mod }}$ to $D C^{\text {mod }}$ is compared to the proportion of utility of component $i$ to the product's total utility. This comparison leads to the calculation of the target cost index, as defined in (2) using modified drifting costs. For the modified target costing, the same implications of the $T C I_{i}$ apply as for the original target costing. If the $T C I_{i}$ is equal to one, the costs are optimized. If the $T C I_{i}$ is not equal to one, costs need to be adjusted. In case the cost structure is not optimized, the proportion of $D C_{i}^{\text {mod }}$ to $D C^{\text {mod }}$ differs from the proportion of utility of the $i^{\text {th }}$ component. The required adjustment in costs can be calculated as follows:

$$
\text { required adjustment in costs }=\left(\frac{D C_{i}^{\text {mod }}}{A C^{\text {mod }}}-\sum_{j=1}^{J}\left(u_{j} \cdot v_{i j}\right)\right) \cdot A C^{\text {mod }} \text {. }
$$

Hence, we subtract the proportion of utility one component has from the proportion of costs of the same component based on $A C^{\text {mod }}$ and multiply the result by $A C^{\text {mod }}$. Overall, our modified model and the original target costing approach result in the same required cost adjustment. Yet, the required adjustments per component $i$ differ. Therefore, indicated required cost adjustments for product components will be biased in the original target costing model. In contrast, our modification based on $A C_{i}^{\text {mod }}$ leads to more reasonable cost adjustments per component $i$ since they take only the portion of costs into account that can actually be optimized with respect to customer utility.

For an easier understanding of our modified procedure, the illustrative example is based on a rather simple product understanding. This holds in particular for the minimum variant. We acknowledge that the majority of real-world applications of target costing will have to deal with complex products and their complex minimum variants. Hardware components are often no longer sufficient to characterize today's product concepts. For instance, manufacturing firms are increasingly shifting to products in the form of hybrid offerings that combine goods and services (e.g., Ulaga and Reinartz 2011) so that certain minimum 
requirements for software, maintenance contracts, real-time and ex-post monitoring may well be necessary depending on the specific product. ${ }^{6}$ This is not only observable in the B2C business but also in the B2B business, in which customers evaluate holistic business solutions instead of isolated products (e.g., Macdonald et al. 2016). Although these more complex product definitions might not be imperative to enable a product's most basic function, they can still be a quite obvious requirement for the product to be acceptable for the consumer such that it makes sense for a producer to consider them in defining the minimum variant. Our modified target costing is able to capture these complex products by defining the minimum variant as a bundle of components belonging to different product functions. In any case the determination of a minimum variant should undergo a considerable amount of scrutiny to ensure that it really fulfills the customer's minimum requirements with respect to all important product functions.

\section{Conclusion}

In this note, we present a modification of original target costing by introducing a minimum variant. Target costing is based on the assumption of preference independence, resulting in the use of additive utility functions. Customer preference analysis is used to assign utilities to the different components of a product. Subsequently, those utilities are used for the customer-oriented optimization of the cost structure. We argue that an additive utility function and, therefore, the independence of customer preferences should not be assumed until a minimum variant of a product is reached. Even though the problem with the requisite assumption for target costing has been raised by other studies, we are first to explicitly include it in the target costing approach. Introducing a minimum variant, our model recognizes and accounts for the limitation of the assumption of preference independence. The modified target costing model helps assign allowable costs more realistically to the product's components and, therefore, leads to an improvement in the calculation of the necessary adjustment in costs for each component. Ultimately, this improves customer-oriented cost structure optimization.

\section{Appendix}

\section{Accounting for preference dependency in target costing - a note: an illustrative example}

We illustrate our modified target costing approach by applying it to a numerical example within the automobile industry. We will focus on the product functions design, comfort, safety, fuel consumption, engine power (HP), and life-time as shown in Table 1 panel A. Each of these functions has three features comprising one with high customer utility, one with a medium customer utility, and one with customer utility of zero (Table 1 panel B). The latter is our minimum variant.

$\overline{6}$ We thank an anonymous referee for valuable comments on modern product definitions. 
Table 1 Car functions

Panel A: car features

Panel B: partial utility

values of the features

\begin{tabular}{llllllll}
\hline Functions & \multicolumn{3}{c}{ Features } & & & Partial-utility values \\
\hline Design & Sportive & Classic & Unremarkable & & 0.70 & 0.50 & 0 \\
Comfort & High & Medium & Low & & 0.60 & 0.50 & 0 \\
Safety & High & Medium & Low & 0.70 & 0.60 & 0 \\
Fuel consumption & Low & Medium & High & & 0.30 & 0.20 & 0 \\
HP & 200 & 100 & 50 & 0.85 & 0.65 & 0 \\
Life-time & 26 & 18 & 14 & 0.65 & 0.55 & 0 \\
\hline
\end{tabular}

Panel A presents the considered functions and their respective features for the illustrative example for three different scenarios

Panel B shows the partial-utility values for the different features of the respective functions

${ }^{a}$ Values should technically be the result of a conjoint analysis. However, since this example merely serves as an illustration on how to solve the limitations of target costing, we assume values to keep the example simple.

The minimum variant in our model is a car with unremarkable design, low comfort, low safety, high fuel consumption, $50 \mathrm{HP}$, and 14 years of life-time. These features lead to a customer utility of zero and, therefore, the total customer utility for the minimum variant is zero in line with our previous definitions. The components of the product are car body, interior, tires and wheel rim, power train, break-system, IT and others. ${ }^{7}$ Producing the minimum variant still leads to costs for the automobile company. We assume $\underline{D C}$ to be $\$ 9,951.25$ per car. To calculate $\underline{A C}$ from (1), we use an average price for compact cars (representing our minimum variant) of $\$ 10,475.00$ and an approximate sales volume for one company of 80,536 cars. $^{8}$ We set the profit margin to $10 \%$ for the minimum variant and use $20 \%$ as a budget to cover selling, general, and administrative costs. The resulting $\underline{A C}$ per unit amount to around $\$ 7,332.00$ per car. In this example, production goes beyond the minimum variant of the product. The favored variant in our model is assumed to have a sportive design, medium comfort, medium safety, medium fuel consumption, $200 \mathrm{HP}$, and a lifetime of 18 years. We approximate $\overline{D C}$ with $\$ 25,827.25$ per car. To calculate $\overline{A C}$ from (1), we use an average price for a medium class car of $\$ 30,385.00$ per car. As sales volume, we assume 508,145 cars. $^{9}$ The total budget to cover selling and administrative costs is $20 \%$ of total sales and the profit margin for the favored variant is $15 \%$. We receive a unit $\overline{A C}$ of $\$ 19,750.00$ per car. With the results above, $A C^{\text {mod }}$ from (3) can be calculated, resulting in $\$ 12,418.00$ per car. The value of $D C^{\text {mod }}$ from (4) is about $\$ 18,495.25$. Taking into account

\footnotetext{
7 To maintain a structured example, we limit the number of the product's functions and components in our calculations. However, the model can be applied to any number of function and component combination. Including the category "others" in the calculations helps to make the assignment of $D C_{i}$ more reasonable since the total DC have to be in proportion with the realizable price of the car in the market.

${ }^{8}$ Based on approximated sales data from a German automotive manufacturer.

9 Based on approximated sales data from a German automotive manufacturer.
} 
Table 2 DC and AC for the minimum variant per component $i$

\begin{tabular}{lrr}
\hline Component & \multicolumn{1}{c}{$\underline{\underline{C}_{i}}$} & \multicolumn{1}{c}{$\underline{A C}_{i}$} \\
\hline Car body & $\$ 1500.00$ & $\$ 1105.19$ \\
Interior & $\$ 1200.00$ & $\$ 884.15$ \\
Tires \& wheel rim & $\$ 300.00$ & $\$ 221.04$ \\
Power train & $\$ 4500.00$ & $\$ 3315.56$ \\
Break-system & $\$ 350.00$ & $\$ 257.88$ \\
IT & $\$ 1400.00$ & $\$ 1031.51$ \\
Others & $\$ 701.25$ & $\$ 516.68$ \\
Sum & $\$ 9951.25$ & $\$ 7332.00$ \\
\hline
\end{tabular}

In Table 2 drifting costs for the minimum variant per component $\left(\mathrm{DC}_{\mathrm{i}}\right)$ and allowable costs for the minimum variant per component $\left(\underline{\mathrm{AC}}_{\mathrm{i}}\right)$ are depicted for each component $i$ of the product

that values for $\underline{D C}$ are given, we can calculate $\frac{A C}{i}$ from (6) by reducing each $\underline{D C}$, by the same factor $A \bar{C} / D C=0.74$ based on the results above. Table 2 presents the results of the calculation. Given the proportion of utility per component $i$ (see Table 3 ), $A C_{i}^{\bmod }$ (8) can be determined and $D C_{i}^{\text {mod }}(11)$ can be calculated with the values given for $\overline{D C}_{i}$ and $\underline{A C}_{i}$ (see Tables 2 and 4).

To conduct a cost-value analysis, we compare our proportion of utility per component and the proportion of costs per component based on $D C^{\text {mod }}$. The ratio of both results in $T C I_{i}$ from (2) shown in Table 5. Based on the $T C I_{i}$, the required absolute adjustment in costs cannot be determined. In order to calculate the cost reduction from (12) that is necessary to optimize the cost structure of the product, we contrast the proportion of utility per component and the proportion of costs per component based on $A C^{\text {mod }}$ (see Table 6). For instance, the proportion of costs based on $A C^{\text {mod }}$ for the car body is equal to $31 \%$ and the proportion of utility for this component is $23 \%$. As a result, the required reduction in costs for the car body equals $8 \%$ of the total $\mathrm{AC}^{\mathrm{mod}}$. The easier way is to subtract $A C_{i}^{\text {mod }}$ from $D C_{i}^{\text {mod }}$. For example, the $D C_{i}^{\text {mod }}$ of the interior are $\$ 2,615.85$ and $A C_{i}^{\text {mod }}$ of the interior are $\$ 1,986.88$, yielding a reduction potential of $\$ 628.97 .{ }^{10}$ Note that costs do not always need to be reduced. As can be seen, the tires \& wheel rim, as well as the break-system, have negative values in the cost adjustment column. This means that, relative to their customer value, the costs are too low and that the company should invest more in these components.

\footnotetext{
${ }^{10}$ Using the original target costing model, we also calculate a total need for cost reduction of \$6,077.25. However, the cost adjustment/reduction for the component power train is $\$ 2,365.00$ compared to $\$ 955.76$ with the modified target costing approach. Therefore, considering the component power train, the original model overestimates the cost reduction need for this component by $147 \%$, which biases the resulting cost adjustments for the other components, since the total amount must remain the same. More detailed comparisons for all components are available upon request.
} 


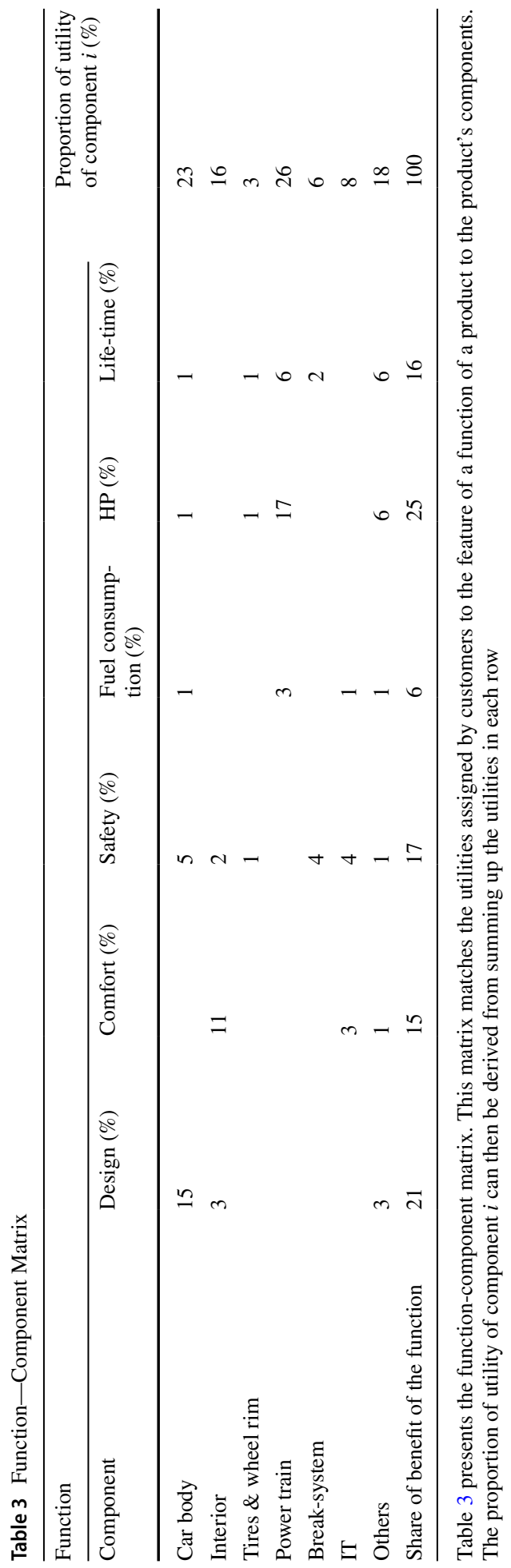


Table 4 DC of the favored variant and modified $\mathrm{DC}$ and $\mathrm{AC}$ per component $i$

\begin{tabular}{lrrr}
\hline Component & \multicolumn{1}{c}{$\overline{D C}_{i}$} & \multicolumn{1}{c}{$D C_{i}^{\text {mod }}$} & \multicolumn{1}{c}{$A C_{i}^{\text {mod }}$} \\
\hline Car body & $\$ 5,000.00$ & $\$ 3,894.81$ & $\$ 2,856.14$ \\
Interior & $\$ 3,500.00$ & $\$ 2,615.85$ & $\$ 1,986.88$ \\
Tires and wheel rim & $\$ 500.00$ & $\$ 278.96$ & $\$ 372.54$ \\
Power train & $\$ 7,500.00$ & $\$ 4,184.44$ & $\$ 3,228.68$ \\
Break-system & $\$ 600.00$ & $\$ 342.12$ & $\$ 745.08$ \\
IT & $\$ 3,500.00$ & $\$ 2,468.49$ & $\$ 993.44$ \\
Others & $\$ 5,227.25$ & $\$ 4,710.57$ & $\$ 2,235.24$ \\
Total costs of the product & $\$ 25,827.25$ & $\$ 18,495.25$ & $\$ 12,418.00$ \\
\hline
\end{tabular}

In Table 4 drifting costs for the favored variant per component $i\left(\overline{D C}_{i}\right)$, modified drifting costs per component $i\left(D C_{i}^{\text {mod }}\right)$, and modified allowable costs per component $i\left(A C_{i}^{\text {mod }}\right)$ are presented for each component

\begin{tabular}{lccc}
\hline Component & $\begin{array}{l}\text { Proportion of util- } \\
\text { ity in } \%\end{array}$ & $\frac{D C_{i}^{\text {mod }}}{D C^{\text {mod }}}$ in $\%$ & $T C I_{i}$ \\
\hline Car body & 23 & 21 & 1.092 \\
Interior & 16 & 14 & 1.131 \\
Tires \& wheel rim & 3 & 2 & 1.989 \\
Power train & 26 & 23 & 1.149 \\
Break-system & 6 & 2 & 3.244 \\
IT & 8 & 13 & 0.599 \\
Others & 18 & 25 & 0.707 \\
Sum & 100 & 100 & \\
\hline
\end{tabular}

Table 5 presents, for each component, the proportion of utility, the proportion of modified drifting costs per component $i\left(D C_{i}^{\text {mod }}\right)$ based on modified drifting costs $\left(D C^{\text {mod }}\right)$, and the target cost index per component $i\left(T C I_{i}\right)$

Table 6 Required adjustments in costs per component $i$

\begin{tabular}{lccrrrr}
\hline Component & $\begin{array}{l}\text { Proportion } \\
\text { of utility } \\
\text { in } \%\end{array}$ & $\begin{array}{l}\text { Proportion of } \\
\text { costs in } \% \text { (of } \\
D C^{\text {mod }} \text { ) }\end{array}$ & $D C_{i}^{\text {mod }}$ & $A C_{i}^{\text {mod }}$ & $\begin{array}{l}\text { Proportion of } \\
\text { costs in } \% \text { (of } \\
A C^{\text {mod }} \text { ) }\end{array}$ & $\begin{array}{l}\text { Required } \\
\text { adjustment in } \\
\text { costs }\end{array}$ \\
\hline Car body & 23 & 21 & $\$ 3,894.81$ & $\$ 2,856.14$ & 31 & $\$ 1,038.67$ \\
Interior & 16 & 14 & $\$ 2,615.85$ & $\$ 1,986.88$ & 21 & $\$ 628.97$ \\
$\quad$ Tires \& wheel & 3 & 2 & $\$ 278.96$ & $\$ 372.54$ & 2 & $\$(93.58)$ \\
$\quad$ rim & 26 & 23 & $\$ 4,184.44$ & $\$ 3,228.68$ & 34 & $\$ 955.76$ \\
Power train & 6 & 2 & $\$ 342.12$ & $\$ 745.08$ & 3 & $\$(402.96)$ \\
Break-system & 6 & 13 & $\$ 2,468.49$ & $\$ 993.44$ & 20 & $\$ 1,475.05$ \\
IT & 8 & 25 & $\$ 4,710.57$ & $\$ 2,235.24$ & 38 & $\$ 2,475.33$ \\
Others & 18 & 100 & $\$ 18,495.25$ & $\$ 12,418.00$ & 149 & $\$ 6,077.25$ \\
Sum & 100 & & & & &
\end{tabular}

Table 6 provides an overview of the proportion of utility, the proportion of costs based on modified drifting costs $\left(D C^{\text {mod }}\right)$, modified drifting costs per component $i\left(D C_{i}^{\text {mod }}\right)$, modified allowable costs per component $i$ $\left(A C_{i}^{\text {mod }}\right)$, and the proportion of costs based on modified allowable costs $\left(A C^{\text {mod }}\right)$ for each component. Furthermore, the right column shows the required adjustment in costs 
Funding Open Access funding enabled and organized by Projekt DEAL.

\section{Declarations}

Conflicts of interest The authors declare that they have no conflict of interest.

Open Access This article is licensed under a Creative Commons Attribution 4.0 International License, which permits use, sharing, adaptation, distribution and reproduction in any medium or format, as long as you give appropriate credit to the original author(s) and the source, provide a link to the Creative Commons licence, and indicate if changes were made. The images or other third party material in this article are included in the article's Creative Commons licence, unless indicated otherwise in a credit line to the material. If material is not included in the article's Creative Commons licence and your intended use is not permitted by statutory regulation or exceeds the permitted use, you will need to obtain permission directly from the copyright holder. To view a copy of this licence, visit http://creativecommons.org/licenses/by/4.0/.

\section{References}

Coenenberg AG, Fischer TM, Günther T (2003) Kostenrechnung und Kostenanalyse, 5th edn. Schäffer-Poeschel, Stuttgart

Dekker H, Smidt P (2003) A survey of the adoption and use of target costing in Dutch firms. Int J Prod Econ 84:292-305. https://doi.org/10.1016/S0925-5273(02)00450-4

Ellram LM (2006) The implementation of target costing in the United States: theory versus practice. J Supply Chain Manag 42:13-26. https://doi.org/10.1111/j.1745-493X.2006.04201003.x

Ewert R, Ernst C (1999) Target costing, co-ordination and strategic cost management. Eur Account Rev 8:23-49. https://doi.org/10.1080/096381899336131

Everaert P, Loosveld S, Van Acker T, Schollier M, Sarens G (2006) Characteristics of target costing: theoretical and field study perspectives. Qualit Res Account Manag 3:236-263. https://doi.org/10.1108/11766 090610705425

Götze U, Linke C (2008) Interne Unternehmensrechnung als instrument des marktorientierten Zielkostenmanagements-ausgewählte Probleme und Lösungsansätze. Zeitschrift für Planung Unternehmenssteuerung 19:107-132. https://doi.org/10.1007/s00187-008-0047-2

Hiromoto T (1988) Another hidden edge - Japanese management accounting. Harv Bus Rev 66:22-26

Ibusuki U, Kaminski PC (2007) Product development process with focus on value engineering and target-costing: a case study in an automotive company. Int J Prod Econ 105:459-474. https://doi. org/10.1016/j.ijpe.2005.08.009

Kato Y (1993) Target costing support systems: lessons from leading Japanese companies. Manage Account Res 4:33-47. https://doi.org/10.1006/mare.1993.1002

Keeney RL (1971) Utility independence and preferences for multiattributed consequences. Operat Res 19:875-893. https://doi.org/10.1287/opre.19.4.875

Macdonald EK, Kleinaltenkamp M, Wilson HN (2016) How business customers judge solutions: solution quality and value in use. J Market 80:96-120. https://doi.org/10.1509/jm.15.0109

Mouritsen J, Hansen A, Hansen CØ (2001) Inter-organizational controls and organizational competencies: episodes around target cost management/functional analysis and open book accounting. Manage Account Res 12:221-244. https://doi.org/10.1006/mare.2001.0160

Navissi F, Sridharan V (2017) Determinants of target costing adoption: a research note. J Manage Account Res 29:67-77. https://doi.org/10.2308/jmar-51501

Sakurai M (1989) Target costing and how to use it. J Cost Manag 3:39-50

Tani T (1995) Interactive control in target cost management. Manage Account Res 6:399-414. https://doi. org/10.1006/mare.1995.1028

Tani T, Okano H, Shimizu N, Iwabuchi Y, Fukuda J, Cooray S (1994) Target cost management in Japanese companies: current state of the art. Manage Account Res 5:67-81. https://doi.org/10.1006/ mare.1994.1005

Ulaga W, Reinartz WJ (2011) Hybrid offerings: how manufacturing firms combine goods and services successfully. J Market 75:5-23. https://doi.org/10.1509/jm.09.0395

Woods M, Taylor L, Fang GCG (2012) Electronics: a case study of economic value added in target costing. Manage Account Res 23:261-277. https://doi.org/10.1016/j.mar.2012.09.002 
Woratschek H (1995) Die preisforschung als informationsgrundlage für das marketing. Handelsforschung 10:153-171

Yazdifar H, Askarany D (2012) A comparative study of the adoption and implementation of target costing in the UK, Australia and New Zeeland. Int J Prod Econ 135:382-392. https://doi.org/10.1016/j. ijpe.2011.08.012

Yoshikawa T, Innes J, Mitchell F (1995) A Japanese case study of functional cost analysis. Manage Account Res 6:415-432. https://doi.org/10.1006/mare.1995.1029

Publisher's Note Springer Nature remains neutral with regard to jurisdictional claims in published maps and institutional affiliations. 